\title{
Mercury resistance as a selective marker for recombinant mycobacteria
}

\author{
Alain Baulard, ${ }^{1}$ Vincent Escuyer, ${ }^{2}$ Nadia Haddad, ${ }^{2}$ Laurent Kremer, ${ }^{1}$ \\ Camille Locht ${ }^{1}$ and Patrick Berche ${ }^{2}$
}

Author for correspondence: Camille Locht. Tel: +33208777 28. Fax: +33 20877906.

\footnotetext{
1 Laboratoire de Microbiologie Génétique et Moléculaire INSERM CJF9109, Institut Pasteur de Lille, 1 Rue du Prof. Calmette, F-59019 Lille Cedex, France

2 Laboratoire de Microbiologie INSERM U411, Faculté de Médecine Necker-Enfants Malades, 156 rue de Vaugirard, 75730 Paris Cedex 15, France
}

\begin{abstract}
The use of antibiotic-resistance markers for the selection of recombinant mycobacteria is widespread but questionable considering the development of live recombinant BCG vaccines. In contrast, vector-encoded resistance to heavy metals such as mercury may represent an interesting alternative for the development of live vaccines compatible with use in humans and in animals. The mercury resistance genes (mer) from Pseudomonas aeruginosa and from Serratia marcescens were cloned into the Escherichia coli-Mycobacterium shuttle vector PRR3. The resulting vectors, designated pMR001 and PVN2, were introduced by electroporation into Mycobacterium smegmatis, Mycobacterium bovis BCG and Mycobacterium tuberculosis. The recombinant mycobacteria were stable in vitro and in vivo, and had high-level mercury resistance, thus indicating that the mer genes can be useful as selective markers in mycobacteria.
\end{abstract}

Keywords: Mycobacterium smegmatis, Mycobacterium bovis BCG, Mycobacterium tuberculosis, mercury resistance, live vaccine

\section{INTRODUCTION}

The genus Mycobacterium encompasses more than 50 species including major human pathogens, such as $\mathrm{Myco-}$ bacterium tuberculosis and Mycobacterium leprae. Mycobacterial infections, especially tuberculosis, remain among the world's leading causes of death, mainly in the developing world. In addition, with the appearance and spread of AIDS, tuberculosis as well as opportunistic mycobacterial infections have re-emerged as serious threats in the United States and in Europe. The recent appearance of multidrug-resistant strains is of especially great concern for public health (Bloom \& Murray, 1992).

Despite the fact that $M$. tuberculosis was one of the first micro-organisms to be recognized as a human pathogen, its molecular genetics remains poorly understood. This may in part be related to the slow growth rate of these organisms, the difficulty of introducing foreign DNA, and the lack of suitable cloning vectors. However, the development of efficient electroporation methods (Snapper et al., 1988), and the construction of autonomously replicating shuttle vectors (Ranes et al., 1990), have, in

Abbreviations: BCG, $M$. bovis bacille Calmette-Guérin; PMA, phenylmercuric acetate. recent years, rendered mycobacteria amenable to molecular investigations.

In addition, several important breakthroughs have led to the promising utilization of attenuated mycobacteria as multiple live-vaccine carriers (Stover et al., 1991). Mycobacterium bovis bacille Calmette-Guérin (BCG) has been used for several decades as a live vaccine against tuberculosis, with a remarkably low record of serious side effects (WHO, 1991). Recently developed molecular tools have opened the possibility of introducing and expressing genes coding for foreign antigens in BCG vaccine strains, and of constructing recombinant multivalent BCG strains capable of immunizing and protecting against multiple infectious diseases simultaneously (Stover et al., 1993).

The cloning vectors currently most widely used in mycobacteria are shuttle plasmids based on pAL5000 isolated from Mycobacterium fortuitum (Labidi et al., 1985), although others, such as pMSC262-derivatives isolated from Mycobacterium scrofulaceum (Goto et al., 1991), and even RSF1010 and its derivatives (Gormley \& Davies, 1991; A. Baulard and others, unpublished) can also be used. Mycobacteria are generally resistant to many antibiotics, probably due to their inherently complex cell wall, and therefore transformed mycobacteria can be selected only by resistance to a limited panel of antibiotics. Thus far, most investigators have used the aph gene which 
Table 1. Bacterial strains and plasmids

\begin{tabular}{|c|c|c|}
\hline Strain or plasmid & Relevant characteristics & Reference/source \\
\hline \multicolumn{3}{|l|}{ Strain } \\
\hline E. coli XL1-Blue & $\begin{array}{l}\mathrm{F}^{\prime}:: \operatorname{Tn} 10 \text { pro } A^{+} B^{+} \text {lac } I^{\mathrm{a}} \Delta(\operatorname{lac} Z) M 15 \\
/ \operatorname{rec} A 1 \text { end } A 1 \text { gyr } A 96\left(\mathrm{Nal}^{\mathrm{r}}\right) \text { thi bsdR } 17 \\
\left(\mathrm{r}_{\mathrm{k}}{ }^{-} \mathrm{m}_{\mathrm{k}}{ }^{+}\right) \text {sup E44 rel } A 1 \text { lac }\end{array}$ & Stratagene \\
\hline M. smegmatis $\mathrm{mc}^{2} 155$ & $\begin{array}{l}\text { Hypertransformable mutant derived from } \\
\text { M. smegmatis } \mathrm{mc}^{2} 6\end{array}$ & Snapper et al. (1990) \\
\hline M. bovis $\mathrm{BCG} 1173 \mathrm{P} 2$ & Vaccine strain & WHO, Stockholm \\
\hline M. tuberculosis $\mathrm{H} 37 \mathrm{Ra}$ & Avirulent $M$. tuberculosis & $\begin{array}{l}\text { Institut Pasteur } \\
\text { Collection }\end{array}$ \\
\hline \multicolumn{3}{|l|}{ Plasmid } \\
\hline pRR3 & $\begin{array}{l}\text { E. coli-mycobacterial shuttle vector } \mathrm{Ap}^{\mathrm{r}} \mathrm{Km}^{\mathrm{r}} \text {, } \\
\text { pAL5000 ori, pUC18 ori }\end{array}$ & Ranes et al. (1990) \\
\hline $\mathrm{pHP} 45 \Omega \mathrm{Hg}$ & $m e r$ from $\operatorname{Tn} 501$ ( $P$. aeruginosa $)$ & Fellay et al. (1987) \\
\hline pLOFHg & mer from pDU1358 (S. marcescens) & Herrero et al. (1990) \\
\hline
\end{tabular}

confers high-level resistance to kanamycin in BCG (Murray et al., 1992; Stover et al., 1991, 1993). However, a few other antibiotic-resistance markers have also been used. Some of these antibiotics, such as streptomycinspectinomycin (Guilhot et al., 1994), have therapeutic value. Since mycobacterial shuttle plasmids can replicate in many mycobacterial species, recombinant BCG might disseminate such antibiotic resistance in nature. The use of broad-host-range vectors, such as RSF1010derivatives, further increases this potential. Therefore it is highly desirable to develop new and safe markers to select recombinant mycobacteria.

The use of resistance to heavy metals, especially mercury, represents an interesting alternative. Mercury and organomercurial compounds are widely distributed in nature and bacterial resistance to mercury is very common in the environment. In addition, many clinical isolates, including most Enterobacteriaceae and almost all Pseudomonas aeruginosa isolates are resistant to mercury (for a review see Robinson \& Tuovinen, 1984).

Mercury resistance is usually determined by plasmids or transposons that contain up to six mer genes; these genes are involved in mercury uptake, resistance or regulation, and are organized in operons (for a review see Misra, 1992). The key enzyme is the mer $A$-encoded mercuric reductase, which reduces $\mathrm{Hg}^{2+}$ to $\mathrm{Hg}^{0}$, a highly volatile compound easily eliminated by the bacterium. Sometimes the operons contain an additional gene, mer $B$, encoding an organomercurial lyase, an enzyme capable of cleaving $\mathrm{C}-\mathrm{Hg}$ bonds to yield $\mathrm{Hg}^{2+}$, which is subsequently reduced by the mer $A$ gene product. Other mer genes are involved in transport or genetic regulation of the operon.

Meissner \& Falkinham (1984) showed that mycobacteria are generally sensitive to mercury and that resistance of some strains is related to the presence of a megaplasmid probably containing mercury-resistance genes. In this study we investigated the possibility of using mer genes from $P$. aeruginosa and Serratia marcescens for the con- struction of useful cloning vectors providing selectable resistance to organic and inorganic mercury in recombinant mycobacteria.

\section{METHODS}

Plasmids, bacterial strains and culture conditions. The plasmids, as well as the Escherichia coli and mycobacterial strains used in this study, are listed in Table 1 . The E. coli strains were grown in LB medium as described by Sambrook et al. (1989). M. smegmatis, M. tuberculosis and $M$. bovis BCG were grown on solid Middlebrook agar $7 \mathrm{H} 10$ (Difco) supplemented with $20 \mathrm{mg}$ kanamycin $1^{-1}$ where indicated or with the indicated concentrations of $\mathrm{HgCl}_{2}$ or phenylmercuric acetate (PMA). Sauton medium (Sauton, 1912) was used for grow th of the mycobacteria in liquid medium.

Genetic constructions. All genetic constructions and plasmid analyses were carried out using standard procedures as described by Sambrook et al. (1989). Electrotransformation of mycobacteria using the Cell Ject apparatus (Eurogentec) and analysis of plasmids by electroduction was performed as described previously (Baulard et al., 1992).

Estimation of mercury MICs. To estimate the MIC, which was defined as the lowest concentration of the mercury compounds at which no bacterial growth was detected, $10 \mu \mathrm{l}$ mycobacterial suspensions $\left(10^{8}-10^{9}\right.$ bacteria $\left.\mathrm{ml}^{-1}\right)$ were spotted onto Middlebrook 7H10 agar, or $100 \mu \mathrm{l}$ of the suspension was inoculated in Roux bottles containing $10 \mathrm{ml}$ liquid medium each supplemented with increasing concentrations of $\mathrm{HgCl}_{2}$ or PMA. The cultures were incubated at $37^{\circ} \mathrm{C}$ for $5 \mathrm{~d}$ (for $M$. smegmatis) or 2-3 weeks (for BCG and M. tuberculosis) until bacterial growth was detected in the controls. As the maximum permitted dose of inorganic mercury vapour, including $\mathrm{Hg}^{0}$, is $50 \mu \mathrm{g} \mathrm{m}^{-3}$, proper ventilation should be used when large quantities of selective growth medium are handled and disposed of. (For a recent review on mercury toxicity, see De Flora et al., 1994.)

Analysis of plasmid stability in BCG. To analyse the stability of the recombinant plasmids, five 6- to 8-week-old female Swiss mice (Charles Rivers, France) were infected intravenously with $5 \times 10^{5}$ BCG(pMR001) or BCG(pVN2). After 2 weeks, their spleens were removed aseptically, homogenized, and serial dilutions were plated onto Middlebrook $7 \mathrm{H} 10$ agar with or 
without $10 \mathrm{mg} \mathrm{PMA}{ }^{-1}$ for BCG(pVN2) or $12 \mathrm{mg} \mathrm{HgCl}_{2} \mathrm{l}^{-1}$ for $\mathrm{BCG}(\mathrm{pMR} 001)$; plates were then incubated for 2 weeks at $37^{\circ} \mathrm{C}$.

\section{RESULTS}

\section{Construction of mycobacterial shuttle vectors containing the mer operons of $\boldsymbol{P}$. aeruginosa and $S$. marcescens}

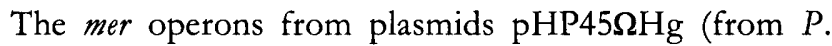
aeruginosa) and $\mathrm{pLOFHg}$ (from $S$. marcescens) were introduced separately into the $E$. coli-mycobacterial shuttle vector $\mathrm{pRR} 3$ using the following cloning strategies. The $4.3 \mathrm{~kb} S m a \mathrm{I}$ fragment of $\mathrm{pHP} 45 \Omega \mathrm{Hg}$, containing the complete Tn 501 mer operon, was inserted into the unique $S c a I$ site of pRR3. After ligation and transformation of $E$. coli XL1-Blue, the transformants were plated onto LB agar supplemented with $12 \mathrm{mg} \mathrm{HgCl}_{2} \mathrm{l}^{-1}$. Mercuryresistant colonies appeared after overnight incubation at $37^{\circ} \mathrm{C}$, whereas no mercury-resistant colonies developed on $\mathrm{LB}$ agar $+\mathrm{HgCl}_{2}$ plated with E. coli XL1-Blue(pRR3). The plasmids from 10 mercury-resistant clones were extracted and analysed, confirming the presence of recombinant plasmids with the expected restriction pattern (data not shown). One of these plasmids, designated pMR001 (Fig. 1a), was then purified by the alkaline-lysis method.

To clone the mer operon from $S$. marcescens into pRR3, a $3 \mathrm{~kb} M l u \mathrm{I}$ fragment was isolated from pLOFHg, bluntended using DNA polymerase I (Klenow fragment) and then inserted into the unique ScaI site of pRR3. The recombinant plasmids were introduced into $E$. coli XL1Blue and the transformants selected on LB agar supplemented with $10 \mathrm{mg}$ PMA $1^{-1}$. After isolation and restriction analysis of the recombinant plasmids, one representative showing the correct restriction pattern was purified and designated pVN2 (Fig. 1b).

\section{Mycobacterial resistance to inorganic mercury in liquid medium}

$M$. smegmatis $\mathrm{mc}^{2} 155, M$. bovis BCG $1173 \mathrm{P} 2$ and $M$. tuberculosis $\mathrm{H} 37 \mathrm{Ra}$ were transformed with pMR001 and pVN2. Since both plasmids contain the aph gene in addition to their mer genes, the transformants were first selected on Middlebrook 7H10 agar supplemented with Middlebrook ADC Enrichment and $20 \mathrm{mg}$ kanamycin $\mathrm{I}^{-1}$. After incubation at $37^{\circ} \mathrm{C}$ for $5 \mathrm{~d}$ (for $M$. smegmatis) or 2-3 weeks (for BCG or $M$. tuberculosis), single kanamycinresistant colonies were obtained for all three mycobacteria. To ensure that the kanamycin resistance was due to the presence of pMR001 or pVN2, four isolated colonies for each species and for each plasmid were analysed by electroduction. All plasmids isolated from the mercury-resistant $E$. coli back-transformants displayed the correct restriction pattern (data not shown). The recombinant mycobacteria were then transferred to mercurycontaining growth medium to assess whether mercuryresistance could be expressed in mycobacteria using the mer genes from $P$. aeruginosa or $S$. marcescens.
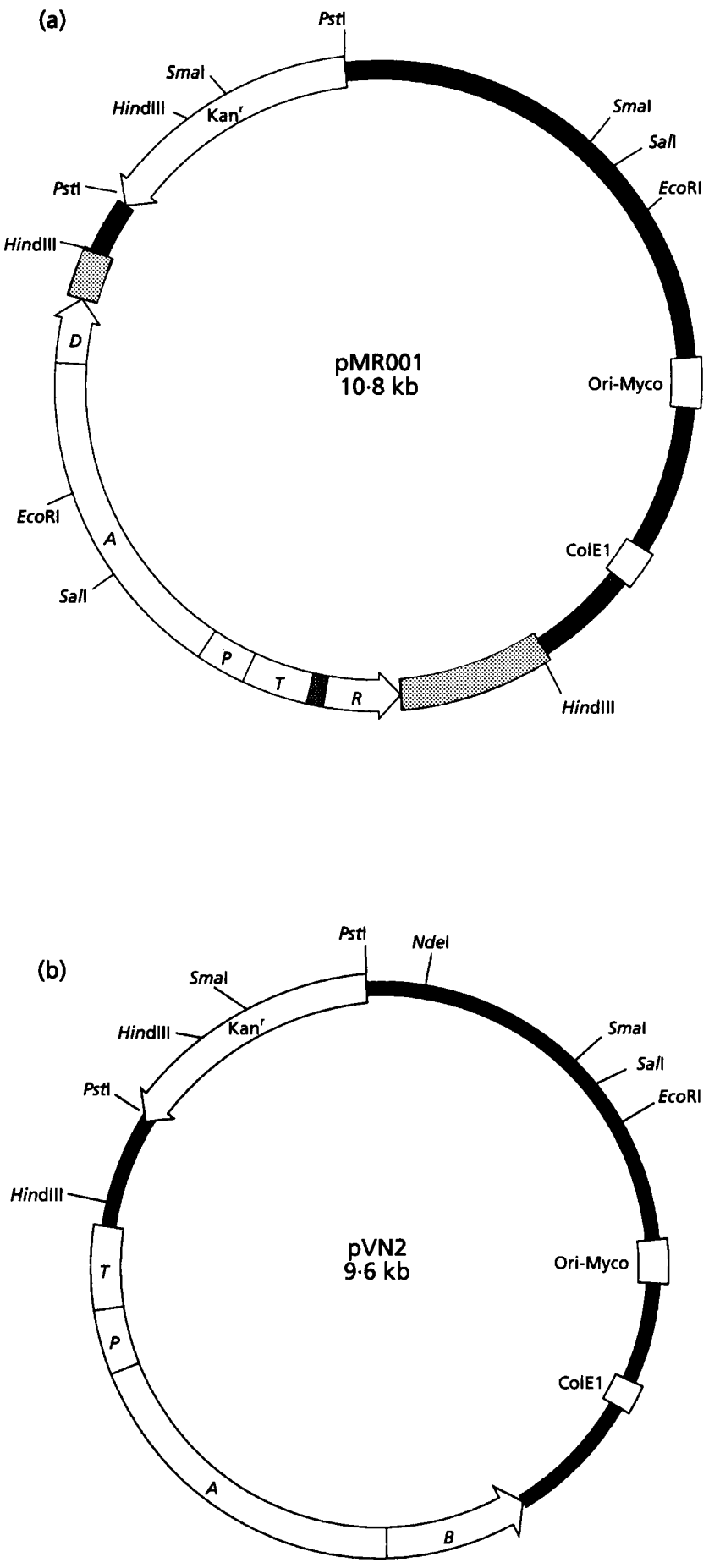

Fig. 1. Partial restriction map of pMR001 (a) and pVN2 (b). The thick black line represents DNA originating from pRR3. The open boxes within the black line represent the ColE1 and mycobacterial origins of replication as indicated. The open arrow within the black line represents the kanamycin-resistance gene from Tn903. The open arrows within the grey box show the merRTPAD genes from Tn501 (a) or the merTPAB genes from pDU1358 (b) as indicated. The direction of transcription of the different genes is indicated by the arrows. 
Table 2. Expression of mercury resistance in mycobacteria harbouring mycobacterial shuttle vector pRR3, and its derivatives pMR001 or pVN2

\begin{tabular}{|c|c|c|c|c|}
\hline \multirow{2}{*}{ Plasmid* } & \multirow{2}{*}{$\begin{array}{c}\text { Mercury } \\
\text { compounds }\end{array}$} & \multicolumn{2}{|c|}{$\operatorname{MIC}\left(\mathrm{mg} \mathrm{l}^{-1}\right) \dagger$} & \multirow{2}{*}{$\begin{array}{c}\text { Mercury } \\
\text { resistance } \\
\text { phenotype } \ddagger\end{array}$} \\
\hline & & Solid & Liquid & \\
\hline pRR3 & $\begin{array}{l}\mathrm{HgCl}_{2} \\
\text { PMA }\end{array}$ & $\begin{array}{l}0 \cdot 15 \\
0 \cdot 15\end{array}$ & $\begin{array}{l}<1 \cdot 25 \\
<0 \cdot 15\end{array}$ & $\begin{array}{l}\mathrm{S} \\
\mathrm{S}\end{array}$ \\
\hline pMR001 & $\begin{array}{l}\mathrm{HgCl}_{2} \\
\mathrm{PMA}\end{array}$ & $\begin{array}{r}160 \\
0 \cdot 6\end{array}$ & $\begin{array}{l}40 \\
\text { ND }\end{array}$ & $\begin{array}{l}\mathrm{R} \\
\mathrm{S}\end{array}$ \\
\hline $\mathrm{pVN} 2$ & $\begin{array}{l}\mathrm{HgCl}_{2} \\
\text { PMA }\end{array}$ & $\begin{array}{r}160 \\
40\end{array}$ & $\begin{array}{r}40 \\
5\end{array}$ & $\begin{array}{l}\mathrm{R} \\
\mathrm{R}\end{array}$ \\
\hline
\end{tabular}

ND, Not determined.

* Plasmids conferred the same level of mercury resistance in $M$. tuberculosis, M. smegmatis and M. bovis BCG

$+\mathrm{MIC}$ in Sauton liquid medium or on Middlebrook $7 \mathrm{H} 10$ solid medium.

$\ddagger$ Phenotype on Middlebrook $7 \mathrm{H} 10$ agar supplemented with $12 \mathrm{mg}$ $\mathrm{HgCl}_{2} \mathrm{l}^{-1}$ or $10 \mathrm{mg} \mathrm{PMA} \mathrm{l^{-1 }}$; $\mathrm{S}$, sensitive; $\mathrm{R}$, resistant.

As shown in Table 2, untransformed mycobacteria or organisms transformed with $\mathrm{pRR} 3$ were highly susceptible to mercury. As little as $0 \cdot 15 \mathrm{mg} \mathrm{l}^{-1} \mathrm{HgCl}_{2}$ or PMA in solid medium, and $1.25 \mathrm{mg} \mathrm{l}^{-1}$ or $0.15 \mathrm{mg} \mathrm{l}^{-1} \mathrm{HgCl}_{2}$ or PMA, respectively, in liquid medium, totally inhibited growth. In contrast, growth of pMR001-containing mycobacteria was only inhibited above $160 \mathrm{mg} \mathrm{HgCl}_{2} \mathrm{l}^{-1}$ on solid medium or $40 \mathrm{mg} \mathrm{HgCl}_{2} \mathrm{l}^{-1}$ in liquid medium, whereas they were susceptible to PMA in both media, which was expected. The pVN2-harbouring mycobacteria were found to be as resistant as the pMR001-containing bacteria to $\mathrm{HgCl}_{2}$, but, in addition, showed increased levels of resistance to PMA, with MIC values of $40 \mathrm{mg} \mathrm{l}^{-1}$ and $5 \mathrm{mg} \mathrm{l}^{-1}$ for solid and liquid medium, respectively. Interestingly, similar results were obtained for each plasmid, regardless of which of the three mycobacterial species was analysed.

\section{Plasmid stability in BCG}

The stability of plasmids was analysed by infecting mice with BCG(pMR/001) or BCG(pVN2) and, after 2 weeks, plating serial dilutions of their homogenized spleens onto Middlebrook $7 \mathrm{H} 10$ agar with or without $10 \mathrm{mg} \mathrm{PMA} \mathrm{l^{-1 }}$ for $\mathrm{BCG}(\mathrm{pVN} 2)$ or $12 \mathrm{mg} \mathrm{HgCl}_{2} \mathrm{l}^{-1}$ for $\mathrm{BCG}(\mathrm{pMR} 001)$. After 2 weeks' growth at $37^{\circ} \mathrm{C}$, all plates contained about the same number of viable colonies $\left(10^{5}-10^{6}\right.$ per spleen $)$ regardless of the presence or absence of the mercuric compounds, indicating that $\mathrm{pMR} 001$ and $\mathrm{pVN} 2$ are both highly stable in vivo in the absence of selective pressure.

\section{Direct use of mercury resistance for the selection of recombinant mycobacteria}

To investigate whether mercury resistance encoded by pMR001 or pVN2 can be directly used for the selection of transformed mycobacteria, each plasmid was electro- porated into all three bacterial species and the transformants were directly plated onto Middlebrook $7 \mathrm{H} 10$ agar supplemented with $12 \mathrm{mg} \mathrm{HgCl}_{2} \mathrm{l}^{-1}$ or $10 \mathrm{mg}$ PMA $1^{-1}$. After $5 \mathrm{~d}$ (for M. smegmatis) or 2 to 3 weeks (for BCG or $M$. tuberculosis) of growth at $37^{\circ} \mathrm{C}, 10^{3} \mathrm{HgCl}_{2}$-resistant colonies $\left(\mu \mathrm{g}\right.$ plasmid DNA) ${ }^{-1}$ were obtained for each species and $10^{3}$ PMA-resistant colonies $(\mu \mathrm{g}$ pVN2 DNA $)^{-1}$ were obtained. No growth was observed for either species transformed with pRR3. In all cases, backtransformation to $E$. coli by electroduction confirmed the presence of the expected plasmids in the resistant mycobacterial colonies. Interestingly, the numbers of mercuryresistant clones were generally $2-5$-fold higher than the number of kanamycin-resistant clones after transformation with the same plasmids, suggesting that mycobacteria tolerate selection on mercury better than selection on kanamycin.

\section{DISCUSSION}

The insertion of the mer operons from $\operatorname{Tn} 501$ or from pDU1358 into pAL5000-derivatives resulted in the construction of stable recombinant plasmids which supported the growth of mycobacteria in mercury-supplemented media. These results demonstrate that the mer genes from $P$. aeruginosa or $S$. marcescens are expressed in recombinant mycobacteria and provide useful selectable markers. The introduction of pMR001 or pVN2 in mycobacteria induces high-levels of mercury resistance, with MIC values 40-100-fold greater than background values for $\mathrm{HgCl}_{2}$ and $20-100$-fold for PMA. The MIC values were always lower in liquid medium as opposed to solid medium, most likely because of better exposure of the bacteria to mercurial compounds in liquid medium. Similar levels of resistance were observed with all three mycobacteria tested, suggesting that the copy number of the vectors, as well as the expression levels of the mer genes, are similar in the three organisms, regardless of differences in growth rate. Besides safety considerations, the mer genes studied here offer certain advantages over the most commonly used $E$. coli-derived aminoglycoside phosphotransferase gene, in that selection on mercury compounds gave consistently higher transformation frequencies than selection on kanamycin. A similar observation has also recently been reported when a hygromycin-resistance marker was compared to the kanamycinresistance marker (Garbe et al., 1994). As reported for the use of hygromycin-resistance, selection by mercuryresistance may therefore also be helpful for the transformation of mycobacteria that have so far been refractory to transformation, especially those that are already resistant to the commonly used antibiotics.

Given that the spectra of resistance of the transformed bacteria correspond to that of the introduced respective mer operons (see Table 2), at least the $\operatorname{mer} A$ gene of pMR001 and both the $\operatorname{mer} A$ and $\operatorname{mer} B$ genes of pVN2 are expressed. In addition, both the mercuric reductase and the organomercurial lyase encoded by these genes are enzymatically active within the mycobacterial cell. Whether the other genes of the mer operons, $\operatorname{mer} T, \operatorname{mer} P$ and merD, are also expressed is unknown at present. 
However, it is likely that at least the merT and $\operatorname{mer} P$ genes of both mer operons are also transcribed, because they constitute the first two cistrons in the polycistronic mer operons. Even if these genes are transcribed, it is possible that their products are not needed for mercury resistance in mycobacteria, because, unlike for Gram-negative bacteria, transport proteins are not required for mercurial resistance in Gram-positive bacteria (Silver \& Laddaga, 1990).

The mer operons are most likely expressed under the control of their own promoter sequences in the mycobacteria, because similar levels of resistance are obtained regardless of the orientation of the mer operons in the pRR3 derivative (compare the orientation of the mer genes in pMR001 with that in pVN2; see Fig. 1). Although the two mer operons come from different bacteria, the operator-promoter sequences are almost identical (Griffin et al., 1987; Misra et al., 1984). In addition, deletion of vector DNA upstream of the mer operon, up to the NdeI site of pVN2 shown in Fig. 1(b), did not alter the mercury-resistance pattern of the recombinant mycobacteria (V. Escuyer, unpublished results).

In $P$. aeruginosa and $S$. marcescens, expression of the mer operons is regulated by the merR gene product acting both as a repressor in the absence of $\mathrm{Hg}^{2+}$ and as an activator in the presence of $\mathrm{Hg}^{2+}$. Although pMR001 contains merR, this gene is absent in pVN2. Given that both plasmids provide approximately the same level of resistance to $\mathrm{HgCl}_{2}$, merR is apparently not needed for the expression of the mer operons in mycobacteria, and perhaps is not even expressed in these organisms. In $E$. coli induction of the mer operon by MerR increases expression about 100-fold (Ross et al., 1989). Therefore, one might expect drastically increased mer promoter activity in pMR001 compared to pVN2, if high levels of functional MerR were produced in mycobacteria transformed with pMR001; this was not seen in this study.

\section{Concluding remarks}

Whatever the mechanism of expression of mercury resistance might be in mycobacteria, the $\mathrm{pRR} 3$-derivatives constructed in this study showed high stability both in vitro after several subcultures in the absence of selective pressure (A. Baulard, unpublished observations) and in vivo in the spleen of intravenously infected mice. Their high stability, combined with mercury-resistance markers, is safe for the environment, and in the absence of antibiotic-resistance markers make such vectors ideal tools for the production of heterologous antigens in BCG with the aim of developing new recombinant live vaccines for human and animal use. In addition, recombinant mycobacteria resistant to mercury rather than to antibiotics should facilitate safe molecular approaches for the study of pathogenesis in a wide array of animal models. The use of mercury resistance is, in principle, not limited to the selection of mycobacteria containing recombinant plasmids, but should also prove useful for the selection of chromosomal integration events through transposition, phage integration or recombination. Because of the relatively small quantities of mercury compounds used in laboratory-scale experiments, the release of $\mathrm{Hg}^{0}$ from the recombinant mycobacteria is generally insignificant. The inherent plasmid stability in mycobacteria decreases the need for continued addition of mercury compounds in preparative-scale cultures. If the presence of those compounds in large-scale fermenters is nevertheless required, proper ventilation should prevent the accumulation of toxic mercury vapours.

\section{ACKNOWLEDGEMENTS}

A. B. and V.E. contributed equally to this study. We thank A. Mercenier and D. Marzin for helpful discussion, G. Delcroix for culturing M. tuberculosis, B. Gicquel, H. Krisch and K. Timmis for plasmids, and T. Kieser for M. smegmatis $\mathrm{mc}^{2} 155$. A.B. and L. K. benefited from fellowships from the Région Nord-Pas de Calais. This work was supported by INSERM, Région NordPas de Calais, Institut Pasteur de Lille, the Ministère de l'Enseignement Supérieur et de la Recherche, and the Université Paris V.

\section{REFERENCES}

Baulard, A., Jourdan, C., Mercenier, A. \& Locht, C. (1992). Rapid mycobacterial plasmid analysis by electroduction between Mycobacterium spp. and Escherichia coli. Nucleic Acids Res 20, 4105.

Bloom, B. R. \& Murray, C. J. L. (1992). Tuberculosis : commentary on a reemergent killer. Science 257, 1055-1064.

De Flora, S., Bennicelli, C. \& Bagnasco, M. (1994). Genotoxicity of mercury compounds. A review. Mutation Res 317, 57-79.

Fellay, R., Frey, J. \& Krisch, H. (1987). Interposon mutagenesis of soil and water bacteria. Gene 52, 147-154.

Garbe, T. R., Barathi, J., Barnini, S., Zhang, Y., Abou-Zeid, C., Tang, D., Mukherjee, R. \& Young, D. B. (1994). Transformation of mycobacterial species using hygromycin resistance as selectable marker. Microbiology 140, 133-138.

Gormley, E. P. \& Davies, J. (1991). Transfer of plasmid RSF1010 by conjugation from Eschericbia coli to Streptomyces lividans and Mycobacterium smegmatis. J Bacteriol 173, 6705-6708.

Goto, Y., Taniguchi, H., Udou, T., Mizuguchi, Y. \& Tokunaga, T. (1991). Development of a new host vector system in mycobacteria. FEMS Microbiol Lett 83, 277-282.

Griffin, H., Foster, T. J., Silver, S. \& Misra, T. K. (1987). Cloning and DNA sequence analysis of the mercuric and organomercurial resistance determinants of plasmid pDU1358. Proc Natl Acad Sci US A 84, 3112-3116.

Guilhot, C., Otal, I., Rompaey, I. V., Martin, C. \& Gicquel, B. (1994). Efficient transposition in mycobacteria: construction of Mycobacterium smegmatis insertional mutant libraries. J Bacteriol 176, 535-539.

Herrero, M., de Lorenzo, V. \& Timmis, K. N. (1990). Transposon vectors containing non-antibiotic resistance selection markers for cloning and stable chromosomal insertion of foreign genes in gramnegative bacteria. $J$ Bacteriol 172, 6557-6567.

Labidi, A., David, H. L. \& Roulland-Dussoix, D. (1985). Restriction endonuclease mapping and cloning of Mycobacterium fortuitum var. fortuitum plasmid pAL5000. Ann Inst Pasteur Microbiol 136, 209-215.

Meissner, P. S. \& Falkinham, J. O. (1984). Plasmid-encoded mercuric reductase in Mycobacterium scrofulaceum. J Bacteriol 157, 669-672. 
Misra, T. K. (1992). Bacterial resistances to inorganic mercury salts and organomercurials. Plasmid 27, 4-16.

Misra, T. K., Brown, N. L., Fritzinger, D. C., Pridmore, R. D., Barnes, W. M., Haberstroh, L. \& Silver, S. (1984). The mercury resistance operons of plasmid R100 and transposon Tn501: the beginning of the operon including the regulatory region and the first two structural genes. Proc Natl Acad Sci US A 81, 5975-5979.

Murray, A., Winter, N., Lagranderie, M., Hill, D. F., Rauzier, J., Timm, J., Leclerc, C., Moriarty, K. M., Gheorghiu, M. \& Gicquel, B. (1992). Expression of Escherichia coli $\beta$-galactosidase in Mycobacterium bovis BCG using an expression system isolated from Mycobacterium paratuberculosis which induced humoral and cellular immune responses. Mol Microbiol 6, 3331-3342.

Ranes, M. G., Rauzier, J., Lagranderie, M., Gheorghiu, M. \& Gicquel, B. (1990). Functional analysis of pAL5000, a plasmid from Mycobacterium fortuitum: construction of a 'mini' MycobacteriumEscherichia coli shuttle vector. J Bacteriol 172, 2793-2797.

Robinson, J. B. \& Tuovinen, O. H. (1984). Mechanisms of microbial resistance and detoxification of mercury and organomercury compounds: physiological, biochemical, and genetic analyses. Microbiol Rev 48, 95-124.

Ross, W., Park, S. J. \& Summers, A. O. (1989). Genetic analysis of transcriptional activation and repression in the Tn21 mer operon. $J$ Bacteriol 171, 4009-4018.

Sambrook, J., Fritsch, E. F. \& Maniatis, T. (1989). Molecular Cloning: a Laboratory Manual. Cold Spring Harbor, NY : Cold Spring Harbor Laboratory.

Sauton, M. B. (1912). Sur la nutrition minérale du Bacille Tuberculeux. C R Acad Sci 155, 860-861.
Silver, S. \& Laddaga, R. A. (1990). Molecular genetics of heavy metal resistances of Staphylococcus plasmids. In Molecular Biology of Staphylococci, pp. 531-549. Edited by R. P. Novick. New York: VCH.

Snapper, S. B., Lugosi, L., Jekkel, A., Melton, R. E., Kieser, T., Bloom, B. R. \& Jacobs, W. R. Jr (1988). Lysogeny and transformation in mycobacteria: stable expression of foreign genes. Proc Natl Acad Sci US A 85, 6987-6991.

Snapper, S. B., Melton, R. E., Mustafa, S., Kieser, T. \& Jacobs, W. R. Jr (1990). Isolation and characterization of efficient plasmid transformation mutants of Mycobacterium smegmatis. Mol Microbiol 4, 1911-1919.

Stover, C. K., de la Cruz, V. F., Fuerst, T. R., Burlein, J. E., Benson, L. A., Bennett, L. T., Bansal, G. P., Young, J. F., Lee, M. H., Hatfull, G. F., Snapper, S. B., Barletta, R. G., Jacobs, W. R. Jr \& Bloom, B. R. (1991). New use of BCG for recombinant vaccines. Nature 351, 456-460.

Stover, C. K., Bansal, G. P., Hanson, M. S., Burlein, J. E., Palaszynski, S. R., Young, J. F., Koenig, S., Young, D. R., Sadziene, A. \& Barbour, A. G. (1993). Protective immunity elicited by recombinant bacille Calmette-Guérin (BCG) expressing outer surface protein A (OspA) lipoprotein: a candidate Lyme disease vaccine. J Exp Med 178, 197-209.

WHO. (1991). Expanded Programme on Immunization, update. Stockholm: World Health Organization.

Received 17 October 1994; revised 14 December 1994; accepted 23 December 1994. 